\title{
Detection of Trypanozoon trypanosomes infections on Glossina fuscipes fuscipes (Diptera: Glossinidae) using polymerase chain reaction (PCR) technique in the Blue Nile State, Sudan
}

\author{
Mohammed A. Basheer ${ }^{1 \star}$, Yassir O. Mohammed ${ }^{2}$, Mo'awia M. Hassan ${ }^{1}$, Mohamed A. ${ }^{2}$, \\ Mohamed M. Mohamed-Ahmed ${ }^{3}$ and Intisar E. El Rayah ${ }^{1}$ \\ ${ }^{1}$ Tropical Medicine Research Institute (TMRI), P. O. Box 1304, Sudan. \\ ${ }^{2}$ Veterinary Research Institute (VRI), Animal Resources Research Corporation (ARRC), P. O. Box 8067, Sudan. \\ ${ }^{3}$ Veterinary Medicine and Animal Production College, Sudan University of Science and Technology, Sudan.
}

Accepted 16 November, 2012

\begin{abstract}
Tsetse flies transmit many species of trypanosomes in Africa, some of which are human and livestock pathogens of major medical and socio-economic impact. Identification of trypanosomes is essential to assess the disease risk imposed by particular tsetse populations. The present study was carried out to determine the trypanosomal infection rate of tsetse flies (Glossina fuscipes fuscipes) in the Blue Nile State of Sudan. A polymerase chain reaction (PCR) assay was used because of the inherent difficulty of speciating trypanosomal parasites in the fly. Our results show that $4.44 \%(8 / 180)$ of the flies were positive for a Trypanosoma brucei group. Three of eight positive flies reacted with primers for Trypanosoma b. rhodesiense. We did not detect flies infected with $T$. $b$. gambiense. Thus, the burden of flies harboring $T$. b. rhodesiense and $T$. b. brucei trypanosomes were 1.67 and $2.78 \%$, respectively. This is the first evidence of $T$. b. rhodesiense in the Yabus District. Thus, HAT case-detection active surveillance and tsetse fly control campaigns should be conducted before the establishment of human settlement, investment of natural resources into agricultural and animal husbandry.
\end{abstract}

Key words: Glossina fuscipes fuscipes, Trypanosoma brucei, T. b. gambiense, T. b. rhodesiense, infection rate, PCR technique, Blue Nile State.

\section{INTRODUCTION}

Human African Trypanosomiais (HAT) or sleeping sickness is an extremely fatal neurological disease caused by two protozoan sub-species, T. b. gambiense and $T . b$. rhodesiense. At the end of the $19^{\text {th }}$ century, sleeping sickness decimated about a quarter million people in central Africa including the whole of Uganda, Kenya shore, Rwanda/Burundi, the Congo and northward into Equatoria State of the republic of South Sudan. This devastating epidemic was attributed to $T$. b. gambiense (Ford and Katondo, 1977). However, at that time of the epidemic, there were no alternative effective diagnostic

${ }^{*}$ Corresponding author. E-mail: bashirm59@yahoo.com. Tel: +2490114624863. Fax: +249 (0) 183781845. tools, which might have led to the suspicion that the causative agent was anything other than T. b. gambiense. Nevertheless, an outbreak of epidemic proportions attributed to T. b. rhodesiense was reported along the Sudanese/Ethiopian boarder in the early 1970s (Baker et al., 1970). Considering the current instability of people and livestock due to the civil war in Southern Sudan, there was a high probability of spreading both types of sleeping sickness in Southern Sudan. The republic of Southern Sudan has suffered series of epidemics of HAT (Snow,1984a) that coincides with the security conflict in the country or in neighboring countries. Although Sudan lies at the interface of the geographical distribution of the Rhodesian and Gambian types of sleeping sickness, the disease in Sudan has been mainly of the Gambian type transmitted mostly by Glossina fuscipes fuscipes 
(Mohammed et al., 2010). The latest civil unrest has resulted in a massive resurgence of the disease in the republic of Southern Sudan (Moore et al., 1999; Moore and Richer, 2001; Mohammed et al., 2010).

All tsetse fly species have the potential to harbor pathogenic African trypanosomes under laboratory conditions; nevertheless only few species are epidemiologically associated with the transmission in the field (Itard, 1989).

In general, the majority of tsetse flies are refractory to trypanosome infections. A variety of factors are postulated to affect trypanosome infection rates in Glossina (Wohlford et al., 1999; Krafsur et al., 2000). Empirical data have also shown that some tsetse flies can transmit the pathogenic trypanosomes, but only few species in nature are considered epidemiologically important (Leak and Rowlands, 1997). Although seven species of Glossina were recognized in Sudan (Lewis, 1949), Glossina f. fuscipes has been incriminated as the only vector of $T$. b. gambiense in Southern Sudan (Snow, 1984b). Obtaining accurate information on the natural trypanosome infection rates in Glossina and the adventitious hosts will significantly contribute to a better understanding of the epidemiology of trypanosomes in Sudan (Wolhouse et al., 1993). Trypanosome detection techniques have significantly improved by using very high specific molecular tools (Majiwa and Otieno, 1994; Masiga et al., 1992; McNamara et al., 1995). In this paper, we present the results of experiments performed to identify and estimate the natural Trypanozoon trypanosomes infection rate of G. f. fuscipes in the Yabus district, Blue Nile state, Sudan using a PCR technique.

\section{MATERIALS AND METHODS}

\section{Study area}

The field work was conducted in the Yabus District, Kurmuk Locality in the southern region of the Blue Nile State. This area is located in the south-eastern part of Sudan that borders Ethiopia on the east Kurmuk Locality lies entirely between Latitudes $9^{\circ} 40^{\prime}-10^{\circ} \mathrm{N}$, and Longitudes $30^{\circ} 30^{\prime}-32^{\circ} 45^{`} \mathrm{E}$. The study area lies within the Savannah belt, with extensive clay (flood) plains transected by a vast number of seasonal water courses. The climate is tropical, rain fall decreases from southeast to north with total annual rainfall ranging from 650 to $1200 \mathrm{~mm}$. The most dominant feature of the area is River Khor Yabus which originates in Ethiopia. The vegetation cover is interrupted by several villages, hamlets and numerous plots for subsistence farming (Figure 4). Overall, three main types of vegetation predominate: 1) Riverine gallery forest adjacent to the river; 2) derived savanna woodland lies just in the north east and south of the river; and 3) open savanna woodland forest lies northward.

\section{Capture of flies}

The flies of $G$. $f$. fuscipes were caught using unbaited biconical traps (Challier et al., 1977). Traps were placed $200 \mathrm{~m}$ a part for three days during the dry season. Captured flies (pooled males and females) were collected every $24 \mathrm{~h}$, counted and identified (Pollock, 1992) and examined for tenerality. Only non-teneral male and female flies were separately preserved with ethanol that detect Trypanozoon trypanosomes infection using PCR technique.

\section{Preparation of DNA templates}

The DNA was extracted using Chloroform/lsoamyl alcohol method as described by Winnepenninckx et al. (1993) with some modifications. The ethanol was removed using sterilized pipettes. The fixed flies were left to air dry. Each fly was crushed under liquid nitrogen using sterilized glass pestle, placed in an $1.5 \mathrm{ml}$ Eppendorf tube and incubated in $500 \mu \mathrm{l}$ CITAB lysis buffer (2\% CITAB: 100 mM Tris - HCl PH8: 0.02MEDTA PH8: 1.4 M NaCl) (Navajas et al., 1998). Lastly, the DNA was re- suspended in $200 \mu$ l of PCR water.

\section{PCR amplification}

The Oligonucleotide primers used to amplify the target DNA sequences included $\mathrm{TBR}_{1-2}, \mathrm{SRA}_{\mathrm{A}-\mathrm{E}}$ and TgSGP $\mathrm{FOR}_{\text {-Rev }} \cdot \mathrm{TBR}_{1}: 5-$ GAATATTAAACAATGCGCAG-3; TBR2: 5GACAACAAGTACCTTGGCGC-3 (Masiga et al., 1992); SRA ${ }_{E}$ : 5TACTGTTGTTGTACCGCCGC-3; SRA GACAACAAGTACCTTGGCGC-3, SRA A-E (Gibson et al., 2001); TgsGPFor: 5-GCTGCTGTGTTCGGAGAGC-3; TgsGPRev: 5GCCATCGTGCTTGCCTCTC-3 (Radwanska et al., 2002).

All amplifications were performed using $25 \mu$ lotal volume for one reaction: $5 \mu \mathrm{l}$ of the genomic DNA template, $0.3 \mu \mathrm{M}(0.8 \mu \mathrm{l})$ of each $\mathrm{TBR}_{1}$ and $\mathrm{TBR}_{2}$ primers, $0.25 \mu \mathrm{M}(0.7 \mu \mathrm{l})$ of each $\mathrm{SRA}_{\mathrm{A}}$ and SRA $A_{E}$ primer, $0.25 \mu \mathrm{M}(0.7 \mu \mathrm{l})$ of each $\mathrm{TgsGp}_{\mathrm{For}}$ and $\mathrm{TgsG}_{\mathrm{Rev}}, 200$ $\mu \mathrm{M}(0.25 \mu \mathrm{l})$ of mixed $(20 \mathrm{mM}) \mathrm{dNTPs}, 1 \times \mathrm{PCR}$ buffer $(2.5 \mu \mathrm{l})$ (Solis BioDyne, Estonia ), (0.8 M Tris- $\mathrm{HCl}\left(\mathrm{pH} 9.1\right.$ at $\left.20^{\circ} \mathrm{C}\right), 0.2 \mathrm{M}$ $\left(\mathrm{NH}_{4}\right)_{2} \mathrm{SO}_{4}, 0.2 \% \mathrm{w} / \mathrm{v}$ Tween-20), $1.5 \mathrm{mM}(1.5 \mu \mathrm{l}) \mathrm{MgCl}_{2}$, and $0.05 \mathrm{U} /$ $\mu \mathrm{l}(0.25 \mu \mathrm{l})$ of Taq DNA polymerase $(5 \mathrm{U} / \mu \mathrm{l}$, Solis BioDyne, Esotnia). Approximately, $100 \mathrm{ng}$ of genomic DNA were added to each PCR and sample without DNA were included with each batch of samples tested as negative control.

\section{The PCR conditions}

The reaction mixture for each pair of primers used was cycled in a programmed thermo cycler as follows: for TBR primers, the cycling conditions were: initial denaturation at $95^{\circ} \mathrm{C} / 5 \mathrm{~min}$ (1cycle); denaturation at $94^{\circ} \mathrm{C} / 45 \mathrm{~s}$; annealing at $60^{\circ} \mathrm{C} / 1 \mathrm{~min}$; extension at $72^{\circ} \mathrm{C} / 30 \mathrm{~s}$ (35 cycles); final extension for $5 \mathrm{~min}$ at $72^{\circ} \mathrm{C}$.

For TgsGp primers, cycling conditions were: initial denaturation at $94^{\circ} \mathrm{C} / 5 \mathrm{~min}$; denaturation at $94^{\circ} \mathrm{C} / 30 \mathrm{~s}$; annealing at $55^{\circ} \mathrm{C} / 30 \mathrm{~s}$; extension at $72^{\circ} \mathrm{C} / 30 \mathrm{~s}\left(37\right.$ cycles); final extension at $72^{\circ} \mathrm{C} / 5 \mathrm{~min}$.

For SRA primers, cycling conditions were: initial denaturation at $95^{\circ} \mathrm{C} / 5 \mathrm{~min}$; denaturation at $94^{\circ} \mathrm{C} / 1 \mathrm{~min}$; annealing at $68^{\circ} \mathrm{C} / 1 \mathrm{~min}$; extension at $72^{\circ} \mathrm{C} / 1 \mathrm{~min}(37$ cycles $)$; final extension at $72^{\circ} \mathrm{C} / 10 \mathrm{~min}$. PCR product amplicons were resolved in ethidium bromide - stained $(1.5 \%)$ agarose gel and sized by comparison with markers in the Gene Ruler $^{\text {TM }} 100$ bp DNA ladder (Solis BioDyne, Estonia). Gels were photographed by a digital Gel documentation system (Gel Doc2009, BioRad, UK).

\section{RESULTS}

During the course of the collection period, a total number of 369 flies were collected around Yabus Town (246 flies) and Yabus El Kubree (123 flies). The total percentage teneral was $50.9 \%$ and non-teneral sex ratio (female/male) 
Table 1. Catch composition of $\boldsymbol{G}$. $f$. fuscipes in white biconical trap sited in the River Khor Yabus riverine habitats.

\begin{tabular}{lcccc}
\hline Composition & Male & Female & Total & Sex ratio (female/male) \\
\hline Teneral & 96 & 92 & 188 & 0.96 \\
Nonteneral & 72 & 109 & 181 & 1.51 \\
$\%$ tenerals & 57.1 & 45.8 & 50.9 & - \\
\hline
\end{tabular}



Figure 1. Reveals results of PCR in $2 \%$ agarose gel stained with Ethidium bromide under UV. Samples of G. $f$. fuscipes were

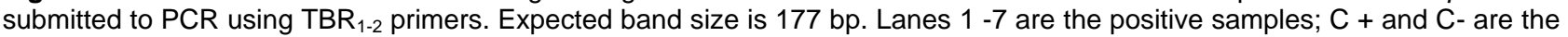
control positive and negative samples; $\mathrm{M}$ is the molecular DNA ladder (100 bp).

was 1.51 fold (Table 1).

\section{Detection of specific T. brucei group DNA-sequence using TBR1 and 2 primers}

Amplification products of the expected band size of 177 bp for TBR gene of Trypanosoma brucei group are clearly visible in Figure 1. The lanes 1 to 8 indicates positive samples of $177 \mathrm{bp}$ PCR product corresponding to the fragment amplified from positive control $\left(\mathrm{C}_{+}\right)$; the positive control DNA used was extracted from FTA cards. Thus, amplification of the crude preparations of templates from a whole fly crushed under liquid nitrogen was possible.

\section{Detection of specific DNA-sequence of $T . \quad b$. rhodesiense using SRA A and E primers}

All samples confirmed positive for T. brucei group by PCR analysis using trypanozoon primers TBR1\&2 screened for the presence of SRA gene. Amplification products of the expected band size of $460 \mathrm{bp}$ for SRA gene of $T$. $b$. rhodisense are clearly visible in Figure 2 ; only 3 out of the 8 samples of flies previously reacted positive with TBR gene. A reference DNA of $T$. b. rhodisense was obtained from TRC-Kenya acting as positive control. This finding pointed out an infection rate of $1.67 \%$ of $T$. b. rhodisense for the first time in the Yabus district, Blue Nile State.

\section{Detection of specific DNA-sequence of $T . \quad b$. gambiense using TgsGP For and Rev primers}

The detection limit of the TgsGp was evaluated on the series of positive control, after a single PCR. The detection limit reached or increased to 10 trypanosomes/l $\mathrm{ml}$ of DNA when the TgsGP was repeated using an aliquot of the first PCR product.

Using primers that distinguish the TgsGP gene of $T$. b.gambiense, a PCR protocol was developed in which a $308 \mathrm{bp}$ PCR product is expected for specific amplification. Results obtained are shown in Figure 3, however, none of the samples reacted positive with TgsGp primers.

\section{Molecular assay analysis}

A total of 180 ethanol-fixed entire bodies of the nonteneral tsetse fly Glossina fuscipes fuscipes collected from River Khor Yabus, Blue NileState, were screened for Trypanozoon trypanosomes infections using polymerase chain reaction (PCR) technique. The results obtained are shown in Table 2 and Figure 1. Out of the 180 G. $f$. fuscipes examined, only $8(4.44 \%)$ reacted positively with TBR1\&2 primers, hence they were considered infected with Trypanozoon trypanosomes of Trypanosoma brucei group: $3(37.5 \%)$ out of these infections reacted positively 


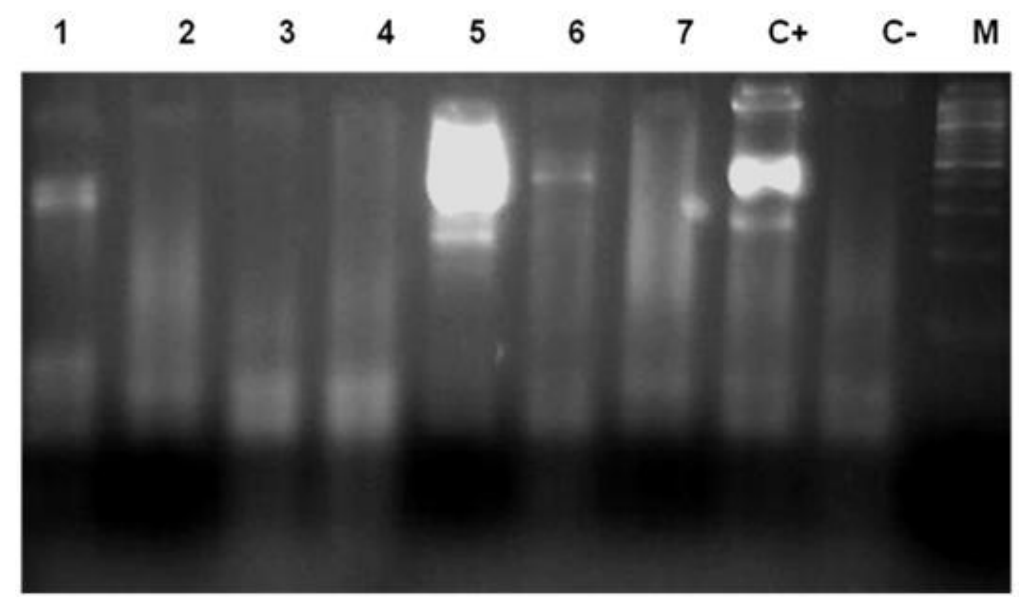

$460 \mathrm{bp}$

Figure 2. Results of PCR in $1.5 \%$ agarose gel electrophoresis stained with ethidium bromide under UV. Samples of the tsetse flies were submitted to the PCR using SRAAE primers for detecting T. b. rhodesiense infection. Expected band size was $460 \mathrm{bp}$; lanes 1, 5, 6 are positive for SRA gene; lane, $\mathrm{C}+$ is the positive control; lane $\mathrm{C}$ - is the negative control; lane $\mathrm{M}$ is 100 bp DNA ladder.

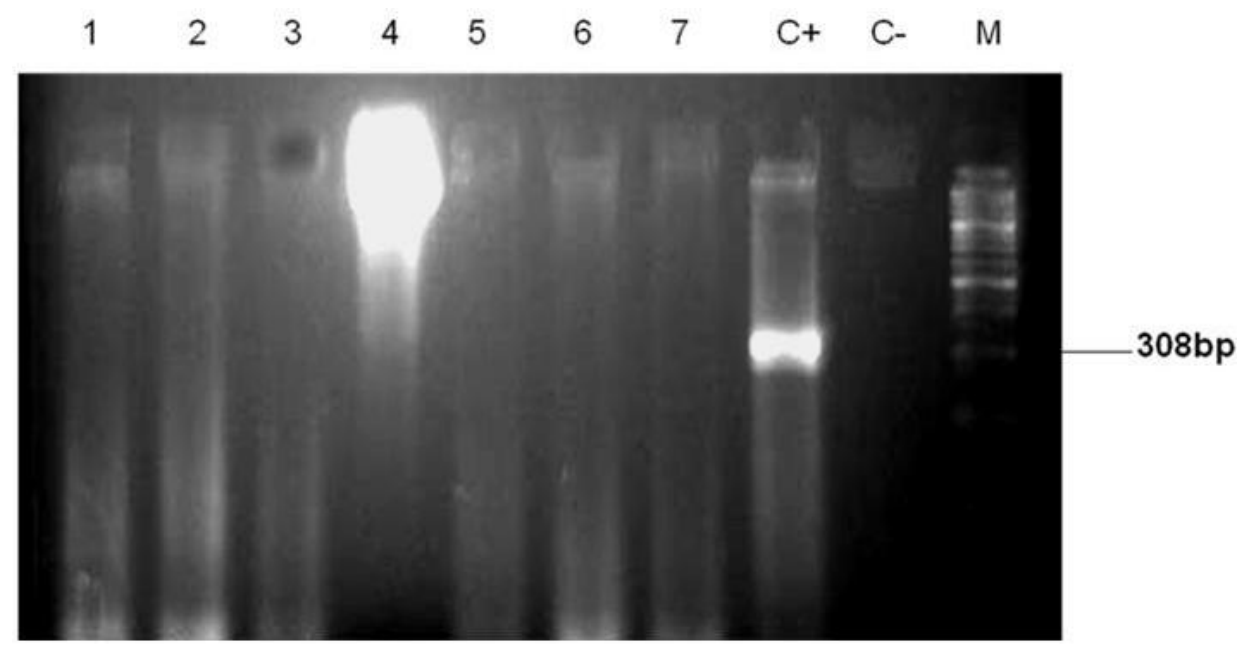

Figure 3. Samples from tsetse flies submitted to the TgsGP primers for the detection of T.b.gambiense. Expected band size for TgsGP gene is $308 \mathrm{bp}$; lanes 1 to 7 are negative samples; lane $\mathrm{C}+$ is the positive control; lane $\mathrm{C}$ - is the negative control; $\mathrm{M}$ is the molecular weight marker (100 bp DNA ladder).

Table 2. Trypanozoon infection rates detected by PCR technique in wild G. f. fuscipes.

\begin{tabular}{lccc}
\hline Fly species & TBR $_{1-2}$ & TgsGP $_{\text {F-R }}$ & SRA $_{\text {A-E }}$ \\
\hline G. f. fuscipes & $4.44 \%(8 / 180)$ & $0.00 \%$ & $37.5 \%(3 / 8)$ \\
\hline
\end{tabular}

with SRA A\&E primers, therefore were considered harboring trypanosomes of $T$. b. rhodesiense, however, none of the examined flies were found infected with $T$. $b$. gambiense as shown by the non reaction with the TgsGP primers. The burden of flies harboring $T$. b. rhodisense and $T$. b. brucei trypanosomes were 1.67 and $2.78 \%$, respectively.

\section{DISCUSSION}

Sudan has experienced a periodic series of HAT epidemics since 1912 (Hutchinson, 1975). These outbreaks coincide with security conflict in the country or in neighboring countries, causing considerable human suffering, varying degrees of mortality and serious loss of 


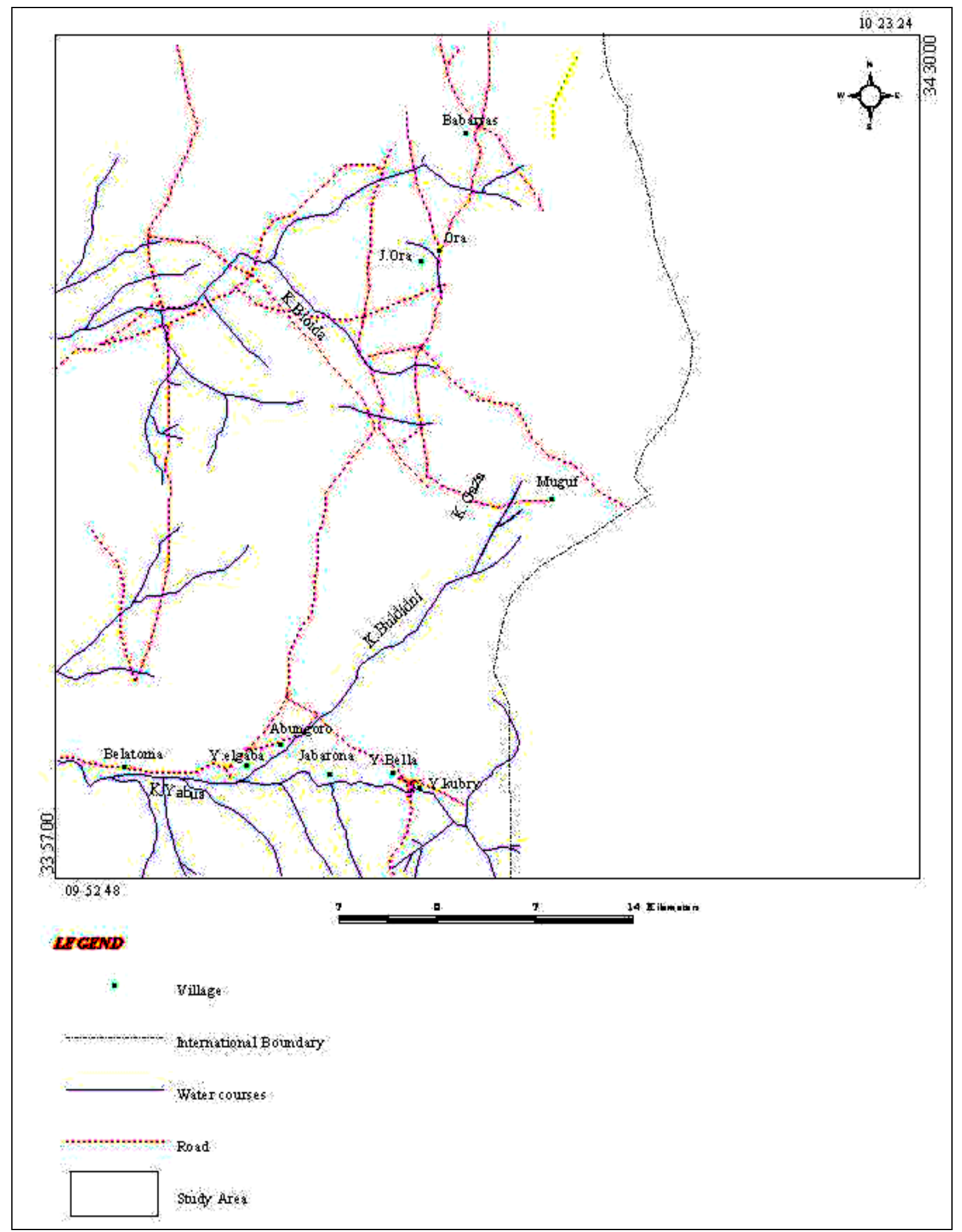

Figure 4. Villages surveyed for tsetse fly occurrence.

efficiency. These epidemics have been attributed to Gambian type of HAT (Mohammed et al., 2010a). Nevertheless, an outbreak of epidemic proportions along the Sudan-Ethiopia border in the Upper Nile State was ascribed to the Rhodesian form (Baker et al., 1970). Since then the exact extent and nature of the disease has remained uncertain. Considering the current instability, there is a high probability of resurgence and spread of the disease in the south-eastern tsetse belt of the Sudan.

The southeastern Sudan tsetse fly region in the Blue 
Nile State comprises a fringe of the Ethiopian tsetse belt within the Sudan frontier. Lewis (1949) described the distribution pattern of Glossina species in the region. Later, tsetse distribution surveys carried out by MohamedAhmed (1989) revealed that only G. $m$. submorsitans and $G$. $f$. fuscipes were encountered and that the fly was restricted to the Khor Yabus District. The latest civil strife has resulted in changes in the vegetation densities and forest extension due to limited human activities and the successive heavy rainy seasons. This has modified the ecology of the area and subsequently the pattern of tsetse flies distribution. The increase in tsetse density with concomitant HAT infections is undoubtedly increasing the risk for both human and animal trypanosomoses (Leak, 1999). Considering the importance of finding $T$. $b$. rhodesiense in the county (Baker et al., 1970), there is a vital need to elucidate the parasite-vector interaction.

Hence, tsetse fly traps were erected to collect flies from the riverine habitats around the most populated villages namely Yabus and Yabus El Kubree. Our results on fly tenerality and sex ratio are in agreement with the study of Flint (1985) and Mohammed et al. (2008).

The traditional trypanosome detection techniques (Lloyd and Johnson, 1924), which relies on microscopic examination, can identify trypanosomes at the subgenus level only and cannot differentiate between brucei groups. The species-specific oligonucleotide primers for PCR amplification have become available for different trypanosome species. Consequently, accurate identification and classification of trypanosomes in archived samples of tsetse to subspecies level is now possible (Stijn et al., 2008). For these reasons, the PCR technique (Masiga et al., 1992) was used in the present study to identify and detect trypanosomes infection.

In the Sudan, G. $f$. fuscipes has been incrimenated as the vector of sleeping sickness, furthermore, using PCR, both types of HAT were detected from wild flies collected from Juba District, Southern Sudan (Mohammed et al., 2010b). Consequently G. f. fuscipes was subjected to screening using PCR to clarify the species of HAT in this study area.

Among the 180 non-teneral $G$. f. fuscipes examined, only $8(4.44 \%)$ reacted positively with TBR $1 \& 2$ primers, consequently they were considered infected with $T$. brucei group. This is verification for the presence of old age category $G$. $f$. fuscipes flies in the area. The longer an infected fly survives, the more likely to become infected with brucei group and greater potential for trypanosome transmission (Tarimo et. al., 1985). However, in nature only a few tsetse fly species are epidemiologically important. Species of Glossina which possess cosmopolitan opportunistic feeding habits, such as $G$. $f$. fuscipes (Mohamed-Ahmed and Odulaja, 1997; Clausen et al., 1998), are more likely to be infected with trypanosomes than those species who usually feed predominantly on readily available mammalian host species or feed on less satisfactory trypanosome reservoirs.
Three $(37.5 \%)$ flies out of the 8 flies harboring brucei infection reacted positively with SRA A\&E primers, hence were considered harboring $T$. b. rhodesiense, however, none of these flies were found infected with $T$. $b$. gambiense. Our results are consistent with the study of Mohammed et al. (2010b) indicating that G. f. fuscipes is a potential vector for $T$. b. rhodesiense and Nagana in the Blue Nile State.

In the present work, the burden of $G$. $f$. fuscipes harboring $T . \quad b$. rhodesiense and $T . \quad b . \quad b r u c e i$ trypanosomes was relatively low (1.67 and 2.78\%, respectively). Our result is consistent with the studies conducted in East and West Africa (McNamara et al., 1995; Woolhouse et al., 1996).

This is the first evidence of $T . b$. rhodesiense in the Yabus District. Thus, HAT case-detection active surveillance and tsetse fly control campaigns should be conducted before the establishment of human settlement, investment of natural resources into agricultural and animal husbandry.

\section{ACKNOWLEDGEMENTS}

We acknowledge the Tropical Medicine Research Institute (TMRI) National Centre for Research (NCR ), Sudan , Khartoum for facilitating this research financially and techniqually. We are grateful to the Animal Research Cooperation for their support through out this study.

\section{REFERENCES}

Baker JR, Mc Connell E, Kent DC, and Hady J (1970). Human trypanosomiasis in Ethiopia. Ecology of Illubabor province and epidemiology in the Baro river area. Trans. Act. Roy. Soc. Trop. Med. Hyg. 64:523 -530.

Challier A, Eyraud M, Lafaye A, Laveissiere C (1977). Amelioration du rendement du piegebiconique pour glossines (Diptera, Glossinidae) par l'emploi d'un cone inferieur bleu. Can. ORSTOM, Ser. Entomol. Med. Parasitol. 15:283-286.

Clausen PH, Adeyemi I, Bauer B, Breloeer M, Salchow F, Staak C (1998). Host preferences of tsetse (Diptera: Glossinidae) based on blood meal identification. Med. Vet. Entomol. 12:169-180.

Flint S (1985). A comparison of various traps for Glossina spp. (Glossinidae) and other Diptera. Bull. Entomol. Res. 75:529-534.

Ford J, Katondo KM (1977). Maps of tsetse fly (Glossina) distribution in Africa 1973, according to sub-generic groups on scale of $1: 5,000,000$. Bull. Anim. Health Prod. Africa. 15:188-194.

Gibson W, (2001). Molecular characterization of field isolates of human pathogenic trypanosomes. Trop. Med. Int. Health 6:401-406.

Hutchinson MP (1975). Assignment report: Trypanosomiasis in Southern Sudan. 29 April1974 - 31 March 1975. WHO, EM/PD/5 (or EM/SUD/MPD/005/FR (UNHCR) (2301)) May 1975.

Itard J (1989). African animal trypanosomoses. In. Troncy PM, Itard J \& Morel PC, Manual of tropical veterinary parasitology. pp. 177-297. (Translated from the 1981 French edition, published by the French Ministry of Cooperation and Development and the Institutd'Elevage et de MédecineVétérinaire des Pays Tropicaux.) CAB International, UK. (ISBN 0-85198-584-X).

Krafsur ES, Madsen M, Wohlford DL, Mihok S, Griffiths NT (2000) . Population genetic of Glossina morsitans submorsitans (Diptera: Glossinidae). Bull. Entomol. Res. 90:329 -335.

Leak S.G.A (1999). Tsetse Biology and Ecology: Their role in the 
epidemiology and control of trypanosomosis. CAB/ Publishing/ILRI., Nairobi, Kenya. p. 568.

Leak S.G.A, Rowlands GJ (1997). The dynamics of trypanosome infections in natural populations of tsetse (Diptera:Glossinidae); studied using wing-fray and ovarian ageing techniques. Bull. Entomol. Res. 87:273-282.

Lewis DJ (1949). The tsetse fly problem in the Anglo-Egyptian-Sudan. Sudan Notes Rec. 30(2):179-210.

Lloyd LL, Johnson WB (1924). The trypanosome infections of tsetse flies in northern Nigeria and a new method of estimation. Bull. Entomol. Res. 14:265-288.

Majiwa PA, Thatthi R, Moloo SK, Nyeko JH, Otieno LH, Maloo S (1994). Detection of trypanosome infections in the saliva of tsetse flies and buffy-coat samples from antigenaemic but aparasitaemic cattle. Parasitology 108:313-322.

Masiga DK, Smyth AJ, Hayes P, Bromidge TJ, Gibson WC (1992). Sensitive detection of trypanosomes in tsetse flies by DNA amplification. Int. J. Parasitol. 22(7):909-918.

McNamara JJ, Laveissiere C, Masiga DK (1995). Multiple trypanosome infections in wild tsetse in Co'te d'lvoire detected by PCR analysis and DNA probes. Acta Trop. 59:85-92.

Mohamed-Ahmed MM, Odulaja A (1997). Dial activity patterns and host preferences of Glossina fuscipes fuscipes along the shores of Lake Victoria, Kenya. Bull. Entomol. Res. 87:179-186.

Mohammed YO, Mohamed-Ahmed MM, El Malik KH, Intisar ER (2008), "Distribution pattern of Glossina fuscipes fuscipes (Diptera: Glossinidae) in Bahr el Jebel State, Southern Sudan." Int. J. Trop. Insect Sci. 27(3/4):210-215.

Mohammed YO, El Malik KH, Mohamed-Ahmed MM, Intisar ER (2010a), "Factors influencing the sero-prevalence of Trypanosoma brucei gambiense sleeping sickness in Juba county, Central Equatoria State, Southern Sudan. J. Pub. Health Epidemiol. 2(5):100-108.

Mohammed YO, Mohamed-Ahmed MM, Lubna TK, Intisar ER (2010b) . Detection of Trypanosoma brucei gambiense and $T$. b. rhodesiense in Glossina fuscipes fuscipes (Diptera: Glossinidae) and Stomoxys flies using the polymerase chain reaction (PCR) technique in Southern Sudan. Afr. J. Biotechnol. 9(38):6408-6412.

Moore A, Richer M (2001). Re-emergence of epidemic sleeping sickness in southern Sudan. Trop. Med. Int. Health 6(5):342-348.

Moore A, Richer M, Enrile M, Losio E, Roberts J, Levy D (1999). Resurgence of sleeping sickness in Tambura County, Sudan. Am. J. Trop. Med. Hyg. 61:315-318.
Navajas M, Lagnel J, Gutierrez J, Boursot P (1998). Species-wide homogeneity of nuclear ribosomal ITS2 sequences in the spider mite Tetranychusurticae contrasts with extensive mitochondrial COI polymorphism. Heredity 80:742-752.

Pollock ME (1992). Description and keys for the identification of Glossina species. In FAO editors. Training Manual for Tsetse Control Personnel. 1:156-201.

Radwanska M, Claes F, Magez S, Magnus E, Pérez-Morga D, Pays E, Büscher P, (2002). Novel primer sequences for a polymerase chain reaction-based detection of Trypanosoma brucei gambiense. Am J. Trop. Med. Hyg. 67:289-295.

Snow WF (1984a). Assignment Report: Further observation on tsetse distribution, ecology and control in relation to sleeping sickness in southern Sudan. 12 February- 13 June 1983, WHO.

Snow WF (1984b). Tsetse feeding habits in an area of endemic sleeping sickness in southern Sudan. Trans. Roy. Soc. Trop. Med. Hyg. 78:413-414.

Stijn D, Koffi M, Jamonneau V, Bonsu FA, Queyson R, Simarro PP, Herdewijn P, Buscher P (2008). Molecular analysis of archived blood slides reveals an atypical human Trypanosoma infection.

Tarimo SRA, Snow WF, Butler L (1985). Trypanosome infections in wild tsetse, Glossina pallidipes Austen on the Kenyan coast. Insect Sci. Appl. 5:415-418.

Winnepenninckx B, Backeljau T, De Wachter R (1993). Extraction of high molecular weight DNA from mollusks. Trends Genet. 9:407.

Wohlford DL, Krafsur ES, Griffiths NT, Marquez JG, Baker MD (1999). Genetic differentiation of some Glossina morsitans submorsitans populations. Med. Vet. Entomol. 13:377-385.

Woolhouse ME, Hargrove JW, McNamara JJ (1993). Epidemiology of trypanosome infections of the tsetse fly Glossina pallidipes in the Zambezi Valley. Parasitology 106:479-485.

Woolhouse MEJ, McNamara JJ, Hargrove JW, Bealby KA (1996). Distribution and abundance of trypanosome (subgenus Nannomonas) infections of the tsetse fly Glossina pallidipes in southern Africa. Mol. Ecol. 5:11-18. 